\title{
SOFTWARE DE EFEITO ESTROBOSCÓPICO POR SUPERPOSIÇÃO DE FRAMES DE VIDEOCLIPES APLICADA NO ENSINO DE CINEMÁTICA ${ }^{+*}$
}

\author{
Omar Cléo Neves Pereira \\ Waldinéia Maria da Silva \\ Ana Claudia Sabino \\ Maria Estela Gozzi \\ Anderson Reginaldo Sampaio \\ Ronaldo Celso Viscovini \\ Departamento de Ciências - UEM \\ Maringá - PR
}

\begin{abstract}
Resumo
Neste trabalho, apresenta-se um software (StroboMovie) desenvolvido para captura de quadros (frames) de videoclipes (formato $M P E G)$ e superposição em uma imagem final. Esse software possibilita, de maneira rápida e direta, selecionar um trecho de vídeo e a taxa de captura de quadros, criando uma imagem com efeito estroboscópico. Foi desenvolvido com o intuito de contribuir no estudo do movimento nas aulas expositivas ou demonstrativas da cinemática. Como exemplo de sua aplicação, apresentou-se o movimento harmônico de um pêndulo simples, queda livre e tentativa de movimento retilíneo uniforme.
\end{abstract}

Palavras-chave: Efeito Estroboscópico. Video Captura. Ensino de Cinemática.

Software of stroboscopic effect by overlapping frames of video clips used in teaching Kinematics

* Recebido: abril de 2012.

Aceito: agosto de 2012.

Cad. Bras. Ens. Fís., v. 29, n. 2: p. 267-282, ago. 2012. 


\begin{abstract}
In this work we present a software (StroboMovie) to capture designed frames of video clips (MPEG format) and superimposed on the final image. Based on the rule of maximum color, this software enables to quickly and directly, select a section of video and frame capture rate, creating an image with stroboscopic effect. We developed this software to contribute in the analysis of movements in class or demonstration of Kinematics. As an example of its application, here: harmonic motion of a simple pendulum, freefall and attempt to uniform rectilinear motion was presented.
\end{abstract}

Keywords: Stroboscopic Effect. Video Capture. Teaching Kinematics.

\title{
I. Introdução
}

O grande diferencial de evolução da espécie humana é a capacidade de manipular o mundo. Para isso, os homens sentiram a necessidade de entender o movimento que os objetos realizavam. Grandes filósofos da antiguidade, como Aristóteles, teorizavam sobre as causas e trajetórias de movimentos como a queda livre e o lançamento de projéteis. Esses movimentos são rápidos e difíceis de acompanhar, o que levou esses pensadores, denominados filósofos naturais, a criarem diferentes descrições, o que gerou controvérsias que duraram milênios. $O$ Movimento Retilíneo Uniformemente Variado (MRUV) da queda livre foi objeto de estudo de Galileu Galilei no século XVI, mesmo tendo sido combatido pela "comunidade científica" de sua época. Como o estudo do movimento é um assunto de extrema importância, este se tornou um dos ramos da física: a cinemática, do grego kinema ( $\kappa l v \eta \mu \alpha)$, que significa movimento.

$\mathrm{O}$ desenvolvimento de tecnologias para registrar o movimento permitiu avanços significativos na cinemática. A fotografia, inventada no século XIX, era capaz de "congelar" o movimento e resolveu muitas dúvidas. Em 1872, o exgovernador da Califórnia Leland Stanford defendeu que, durante o galope, um cavalo tira as quatro patas do chão ao mesmo tempo. Essa discussão era muito popular entre os apreciadores de corridas de cavalo. Stanford decidiu provar cientificamente sua afirmação e procurou o famoso fotógrafo Edward James Muybridge (BURNS, 2010). Em 1877, Muybridge resolveu a questão, conseguindo tirar uma foto do cavalo de corrida Occident "voando" em meio ao galope. Patrocinado por 
Stanford, no ano seguinte, Muybridge desenvolveu um mecanismo destinado ao estudo do movimento que disparava até vinte e quatro câmeras fotográficas sequencialmente, o qual ele chamou de zoopraxiscópio. Na Fig. 1, temos uma sequência de fotos gravadas por um zoopraxiscópio. Essas imagens, obtidas sequencialmente, foram precursoras das filmagens de cinema.

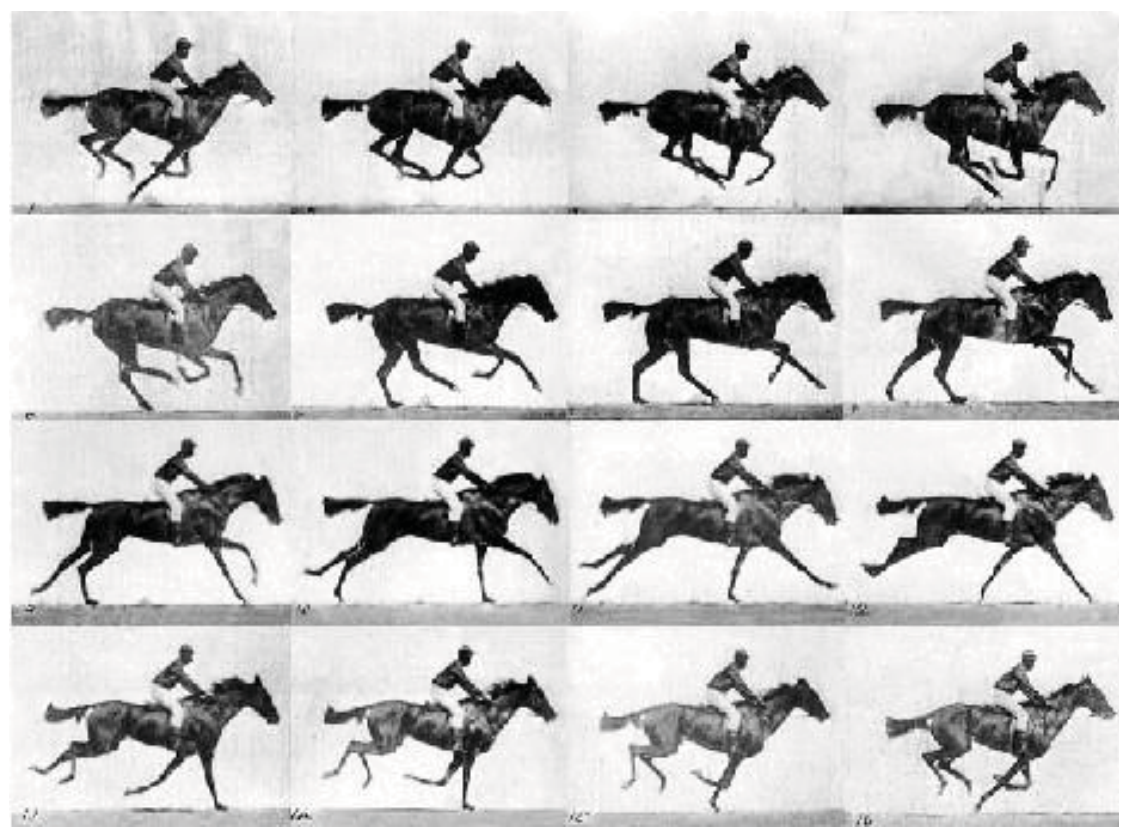

Fig. 1 - Sequência de fotos gravadas pelo zoopraxiscópio de Edward James Muybridge (BURNS, 2010).

No entanto, além da medida da posição, no estudo da cinemática necessita-se da medida do tempo em que o fenômeno observado ocorre. Contudo, fenômenos muito rápidos apresentam dificuldades nas medidas do tempo, fazendo-se necessária a introdução de sofisticados instrumentos de medida, como relógios elétricos chaveados, células fotoelétricas conectadas à interface de um computador que registram o momento da passagem de um objeto, e câmeras fotográficas expostas à luz estroboscópica. Esses equipamentos só estão disponíveis às instituições com laboratórios próprios e que tenham recursos financeiros para adquiri-los.

Com o objetivo de contribuir para o estudo do movimento, algumas soluções foram propostas. Desenvolveram-se softwares que analisam imagens e ví- 
deos, tais como o Tracker - Video Analysis and Modeling Tool (BROWN, 2012) do Cabrillo College; o SAM - Sistema Digital para Análise de Movimentos (MINATEL, 2005; MAGALHÃES, 2002), do Centro de Divulgação Científico e Cultural (CDCC) da USP / São Carlos; além dos métodos de análise direta (CORVELONI, 2009). Esses softwares e métodos permitem estudar com precisão os movimentos, sendo muito utilizados em aulas de física experimental. No entanto, devido à escassez de tempo nas aulas expositivas ou demonstrativas, especialmente no ensino fundamental e médio, a utilização desses recursos, os quais demandam grande quantidade de tempo para a preparação/utilização/análise, torna-se limitada.

Outra proposta para a observação de eventos de curta duração é a fotografia estroboscópica (ROSA, 2004), que pode revelar aspectos qualitativos e quantitativos do movimento, conforme mostrado na Fig. 2. De forma concisa, essas fotografias são obtidas em salas escurecidas, expondo-se um filme fotográfico à luz estroboscópica. Contudo, as dificuldades técnicas e econômicas na obtenção desse recurso didático não permitiram sua difusão.

Hoje, porém, o advento de novas tecnologias possibilita a criação de diferentes oportunidades (AGUIAR, 2006). As câmeras fotográficas digitais expandiram suas funcionalidades e a maioria delas também realiza filmagens. Mesmo câmeras básicas de baixo custo gravam pequenos filmes, conhecidos como videoclipes.

Dias et al. (2009) propuseram um interessante método alternativo e de baixo custo para as fotografias estroboscópicas. Um filme de curta duração do movimento que se deseja estudar, feito por uma câmera fotográfica digital comum, é transferido para um computador, onde, primeiramente o software VirtualDub seleciona o trecho desejado e o decompõe em uma sequência de imagens (frames) individuais que ficam armazenadas no computador; depois, o software ImageJ sobrepõe todos os frames em uma única imagem, a fotografia digital estroboscópica. Ambos os softwares, VirtualDub e ImageJ, são de acesso gratuito. Entretanto, devido à necessidade de aquisição de dois softwares com um grande número de comandos para se obter a imagem estroboscópica, esse método acaba dispersando a atenção do aluno e dificultado o seu uso em sala, especialmente em aulas expositivas, quando se pretende uma visualização rápida de diferentes movimentos feitos em tempo real. Também Sismanoglu (2009) utilizou uma filmadora digital e o software de domínio público VirtualDub para o estudo do movimento dos corpos. 


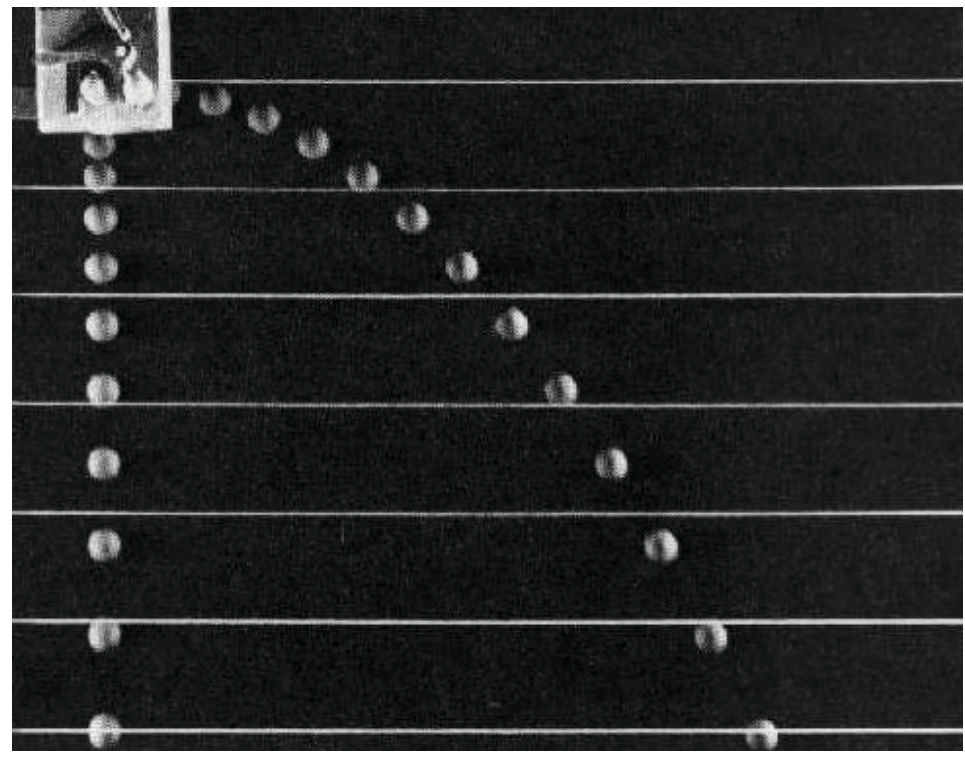

Fig. 2 - Foto estroboscópica de uma queda-livre simultânea com um lançamento horizontal (PEDUZZI, 1998).

Desse modo, apresenta-se, neste trabalho, um software desenvolvido pelos autores (StroboMovie) que, com poucos comandos, extrai quadros (frames) de uma filmagem e os superpõe em uma imagem final, criando um efeito estroboscópico. Esse software, criado especificamente para a produção de imagens estroboscópicas, permite, rapidamente, mostrar a trajetória de um movimento gravado. Como exemplo do emprego do software no ensino de física, utilizaremos videoclipes gravados em sala de aula, por câmeras digitais, para o estudo de alguns movimentos interessantes.

\section{Luz visível e cores}

Para entender a superposição de imagens utilizada na criação desse software, é necessário compreender primeiramente o que é uma imagem colorida e como ela é adquirida por uma câmera ou filmadora digital. A luz visível é uma onda eletromagnética com comprimento de onda em um intervalo em que o olho humano é sensível. Essa região compreende as radiações com comprimentos de ondas entre $400 \mathrm{~nm}$ a $700 \mathrm{~nm}$. Nesse intervalo, temos um contínuo de cores conhecido como arco-íris de Maxwell, mostrado na Fig. 3. 


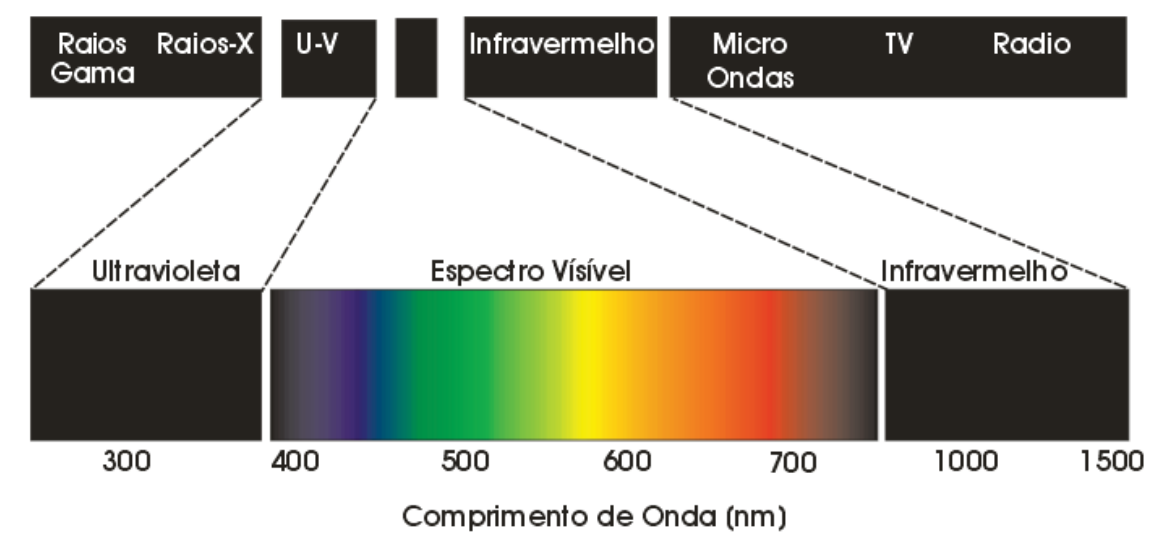

Fig. 3 - Espectro das cores da luz visível (arco-íris de Maxwell).

O olho humano é um sensor óptico, onde uma imagem é projetada por uma lente (cristalino) em uma superfície fotossensível chamada retina. Na retina, existem dois tipos de células fotossensíveis: os bastonetes e os cones (GUYTON, 2006). Os primeiros, em número aproximado de 100 milhões, muito sensíveis, apresentam uma curva de sensibilidade relativa (X) centrada em 530nm, conforme apresentado na Fig. 4. Os cones, com número próximo a 6 milhões, e cerca de 100 vezes menos sensíveis que os bastonetes, são de três tipos: vermelhos (R), verdes (G) e azuis (B), com curvas de resposta próprias para o espectro de cores, conforme mostra a Fig. 4.

Enquanto os sensíveis bastonetes são responsáveis pela percepção das formas e da luminosidade, a percepção de cores depende da combinação dos sinais dos três diferentes cones. Por isso a visão humana é tricrômica, ou seja, uma cor qualquer $(C)$ é função de três variáveis: quantidade de vermelho $(R)$, de verde $(G)$ e de azul $(B)$.

$$
C=f(R, G, B)
$$

As câmeras e filmadoras digitais tentam copiar o olho humano, nas quais a retina é substituída por um sensor óptico composto por uma matriz bidimensional de receptores ópticos. Esses sensores normalmente têm milhões de receptores. Assim como os cones do olho, os receptores de luz dos sensores costumam ser de três tipos, conforme a sensibilidade de cor: $\operatorname{red}(\mathrm{R})$, green $(\mathrm{G})$ e blue $(\mathrm{B})$. 


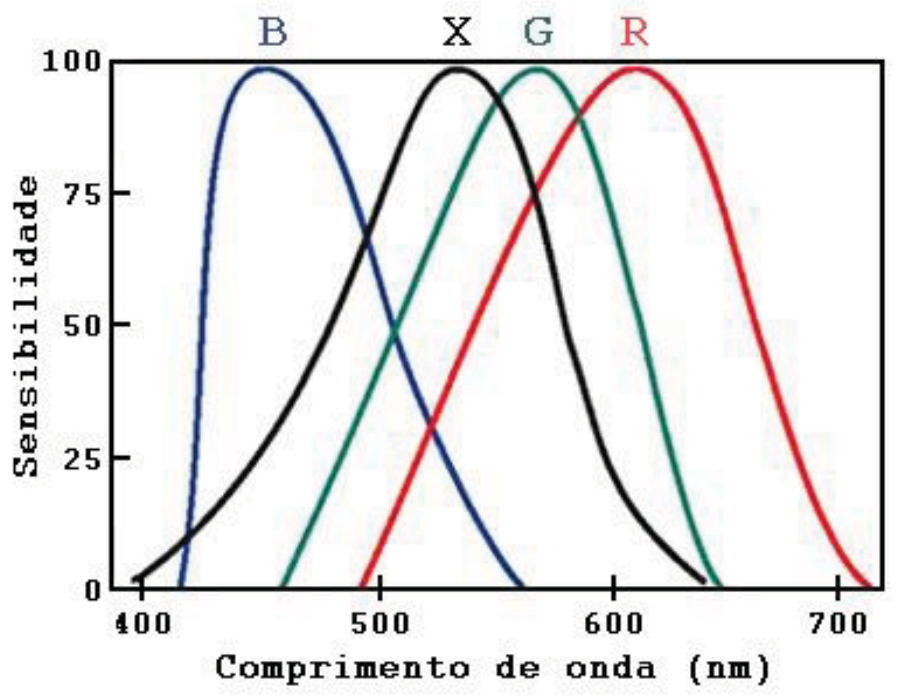

Fig. 4 - Sensibilidade relativa a comprimentos de ondas dos bastonetes $(X)$, e dos cones vermelhos $(R)$, verdes $(G)$ e azuis $(B)$.

As imagens adquiridas pelas câmeras e filmadoras digitais são armazenadas em memórias eletrônicas como matrizes de valores inteiros (discretos). Por isso, a intensidade luminosa em cada trinca de receptor de luz (pixel) tem que ser transformada em valores discretos por meio de conversores analógico-digitais $(A D C)$. No final, uma imagem se torna uma matriz bidimensional de pixels, em que cada pixel é um conjunto de três números inteiros positivos ( $R, G, B)$.

Neste trabalho, foi necessário sobrepor várias imagens (frames) em uma imagem final, sobrepondo os pixels correspondentes de cada uma. Dessa forma, foi necessário definir uma regra de superposição de pixel.

\section{Desenvolvimento do StroboMovie}

No desenvolvimento do software StroboMovie, que a partir de videoclipes de curta duração produz uma imagem estroboscópica, foi preciso criar uma regra para a sobreposição dos frames gerados durante a gravação. Para isso, foram utilizados espaços vetoriais, que são estruturas matemáticas extremamente úteis para representar grandezas físicas. 
Como as cores digitais são um conjunto de três números inteiros (R, G, $B)$, elas podem ser consideradas vetores pertencentes a um subespaço do espaço vetorial inteiro tridimensional $\left(Z^{3}\right)$, em que os valores de $R, G$ e $B$ não podem ser negativos e nem maiores que um valor máximo. Para representá-las nesse espaço vetorial, criou-se uma base ortonormal com cores básicas:

$$
\hat{r}=(1,0,0), \hat{g}=(0,1,0), \hat{b}=(0,0,1) .
$$

Qualquer vetor de cor $\vec{C}_{i}$ de componentes inteiras $\left(R_{i}, G_{i}\right.$ e $\left.B_{i}\right)$ pode ser escrito nesta base, ou seja,

$$
\vec{C}_{i}=R_{i} \hat{r}+G_{i} \hat{g}+B_{i} \hat{b}
$$

em que as componentes $R_{i}, G_{i}$ e $B_{i}$ são números inteiros não negativos dentro de um intervalo limitado, geralmente entre 0 e 255 . Portanto, o conjunto de cores possíveis é limitado sendo um subconjunto do espaço euclidiano discreto tridimensional $\left(Z^{3}\right)$.

Graficamente, podemos representar esse vetor cor $\left(\vec{C}_{i}\right)$ no espaço tridimensional, conforme Fig. 5.

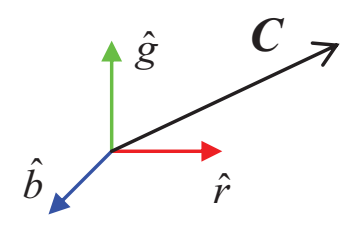

Fig. 5 - Vetor cor $\left(\vec{C}_{i}\right)$ representado na base $(\hat{r}, \hat{g}, \hat{b})$.

A sobreposição de imagens (estroboscópico) é feita pela superposição dos vetores de cor (pixels) correspondentes de cada imagem, ou seja, os pixels que ocupam a mesma posição nas imagens. Uma possibilidade para fazer isso é o cálculo da média $\left(\vec{C}_{\text {Med }}\right)$ dos $n$ vetores de cor a serem superpostos:

$$
\vec{C}_{\text {Med }}=\frac{1}{n} \sum_{i=1}^{n} C_{i}=\frac{1}{n}\left(\sum_{i=1}^{n}\left(R_{i}\right) \cdot \hat{r}+\sum_{i=1}^{n}\left(G_{i}\right) \cdot \hat{g}+\sum_{i=1}^{n}\left(B_{i}\right) \cdot \hat{b}\right)
$$

Para ser um vetor de cor válido, ou seja, de componentes inteiras, é necessário um arredondamento. Infelizmente, o cálculo da média $\left(\vec{C}_{\text {Med }}\right)$ privilegia os 
vetores de cor mais comuns, diluindo os vetores de cor que evidenciam as mudanças da imagem, por isso, não é a melhor escolha para este estudo.

No intuito de preservar o máximo de objetos coloridos na imagem final, utilizou-se a regra da máxima cor possível ( $\vec{C}_{\text {Max }}$ ), em que se escolhe como componente de cor final $\left(R_{M a x}, G_{M a x}\right.$ ou $\left.B_{M a x}\right)$ o valor máximo (Max) de cada uma das componentes de cor $\left(R_{i}, G_{i}\right.$ ou $\left.B_{i}\right)$ de todos os pixels:

$$
\vec{C}_{\text {Max }}=\left(R_{\text {Max }}\right) \hat{r}+\left(G_{\text {Max }}\right) \hat{g}+\left(B_{\text {Max }}\right) \hat{b}=\stackrel{n}{\operatorname{Max}}\left(R_{i}\right) \hat{r}+\underset{i=1}{\max }\left(G_{i}\right) \hat{g}+\underset{i=1}{\operatorname{Max}}\left(B_{i}\right) \hat{b}
$$

onde o operador $\underset{i=1}{\max }\left(X_{i}\right)$ retorna ao maior valor do conjunto $X_{i}$. Essa é a regra para a sobreposição de imagens usada pelo StroboMovie.

É importante salientar que o videoclipe a ser trabalhado no StroboMovie deve estar no formato MPEG (Moving Picture Experts Group), que é, geralmente, o formato dos filmes gravados pelas câmeras digitais. Esse modelo foi padronizado pela primeira vez 1988 pela ISO (International Organization for Standardization). O formato procura otimizar a relação qualidade e tamanho do arquivo de vídeo, combinando técnicas de compressões espacial e temporal. A compressão espacial é baseada na eliminação de redundância de dados em uma imagem estática, como acontece no formato JPEG (Joint Photographic Experts Group). Na compressão temporal uma imagem é a combinação da anterior (e/ou posterior) e informações sobre seus pontos diferentes. Os softwares para gravação em MPEG precisam criar uma sucessão inteligente de compressões espacial e temporal, minimizando a perda de qualidade e o tamanho de arquivo. Para leitura e reprodução de arquivos MPEG é necessário realizar as descompressões. Algumas câmaras gravam em outros formatos, como MOV ou AVI, que podem ser convertidos em MPEG para serem usados no StroboMovie.

Na realização deste trabalho, o software StroboMovie foi desenvolvido em linguagem de programação Delphi ${ }^{\circledR}$ versão 7.0 (TEIXEIRA, 2000; AYRES, 2000). Para auxiliar no processamento de vídeo, utilizou-se a biblioteca DSPack Components and class to Multimedia Application de código aberto (open source) (GOURVEST, 2010). As classes utilizadas da biblioteca DsPack são TFilterGraph; TSampleGrabber; TDSTrackBar e TDSVideoWindowEx2. 


\section{Montagem experimental e testes}

A montagem experimental é simples. Com uma câmera digital fixa em um tripé defronte a uma parede bem iluminada (DIAS, 2009), faz-se um videoclipe do movimento que se deseja estudar. Neste trabalho, utilizou-se uma câmera com resolução VGA (640x480 pixels) que grava a uma taxa de trinta quadros (frames) por segundo. Com o videoclipe pronto, usa-se o software para gerar a imagem estroboscópica. O uso desse software é muito intuitivo, apresentando um tutorial de operação na tela inicial, conforme mostrado na Fig. 6.

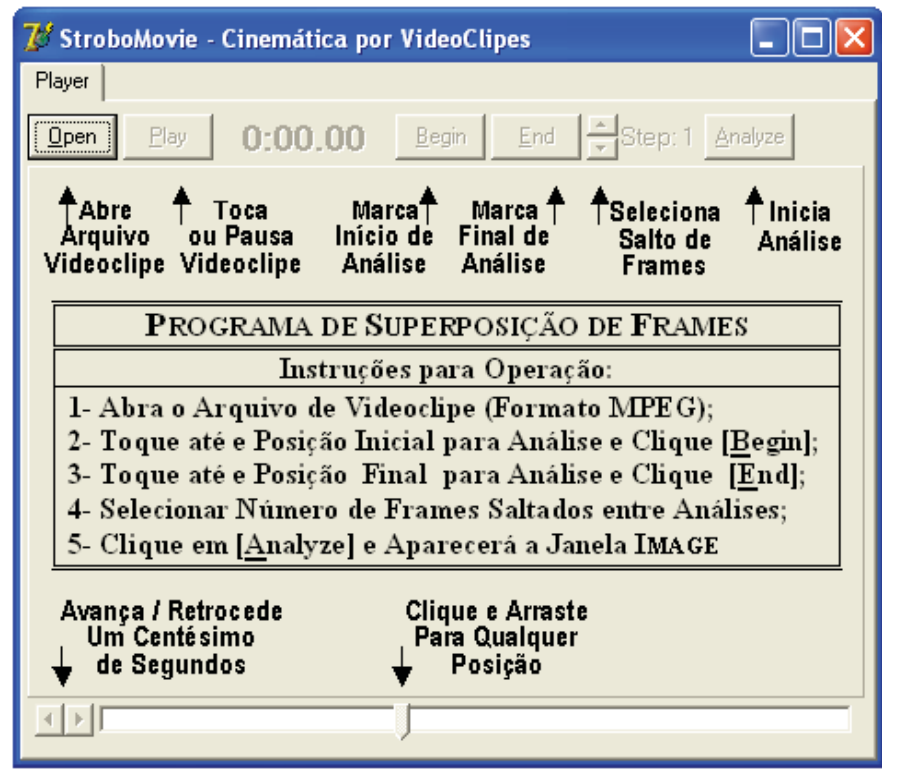

Fig. 6-Página inicial do StroboMovie, com o tutorial de operação.

Como exemplo do uso desse software no estudo dos movimentos, tem-se o pêndulo simples. A Fig. 7 mostra a tela do software StroboMovie após a leitura do videoclipe de um pêndulo simples oscilando em torno de uma posição de equilíbrio.

Desse videoclipe, selecionou-se um trecho correspondente a meio período de oscilação, com aproximadamente um segundo de duração e equivalente a trinta frames. A Fig. 8 mostra o resultado da análise desses trinta frames.

O software StroboMovie permite configurar os passos (Step) para a seleção dos frames que comporão a imagem estroboscópica. Isso pode melhorar a 
visualização do movimento. Como exemplo desse mecanismo, configurou-se o StroboMovie para analisar um a cada três quadros (Step: 3 ) do mesmo trecho do videoclipe analisado acima. O resultado é mostrado na Fig. 9, onde é possível uma análise mais detalhada do movimento.

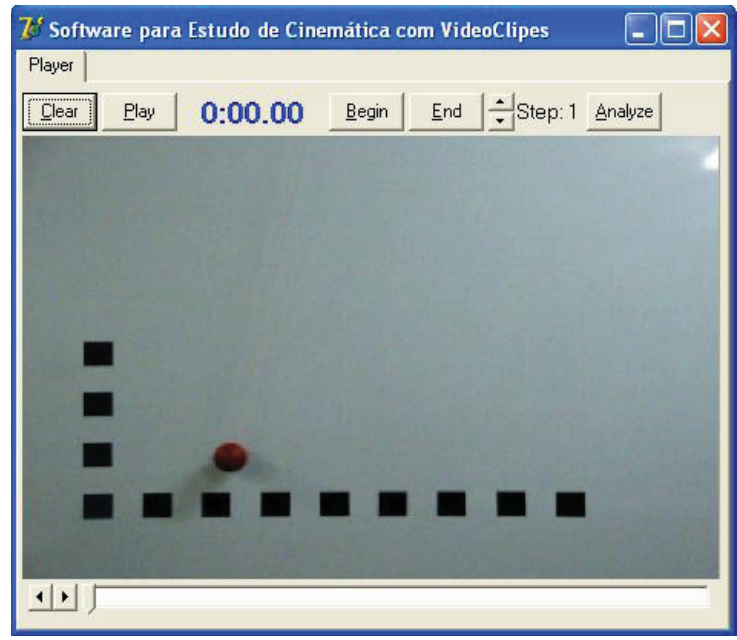

Fig. 7 - Tela do StroboMovie, com o videoclipe de um Pêndulo Simples.

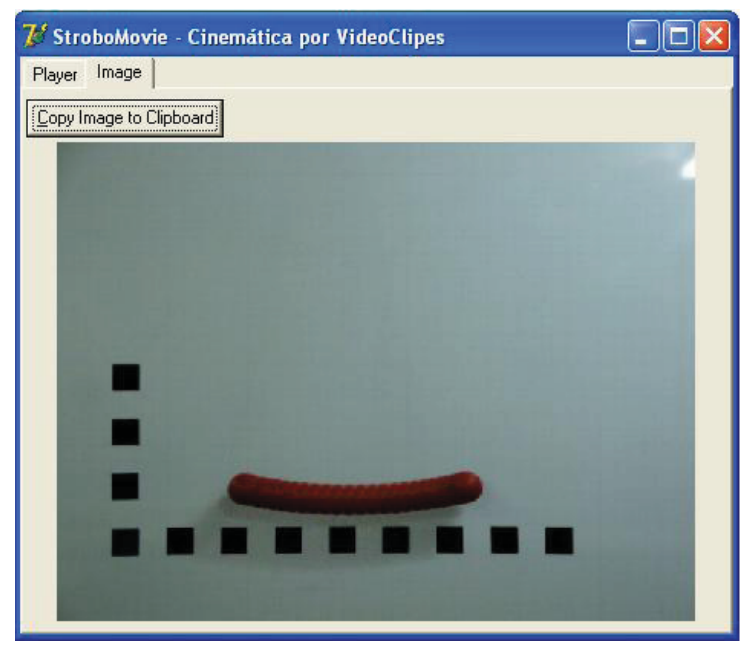

Fig. 8 - Superposição de 30 frames do movimento de um Pêndulo Simples, com duração de um segundo. 


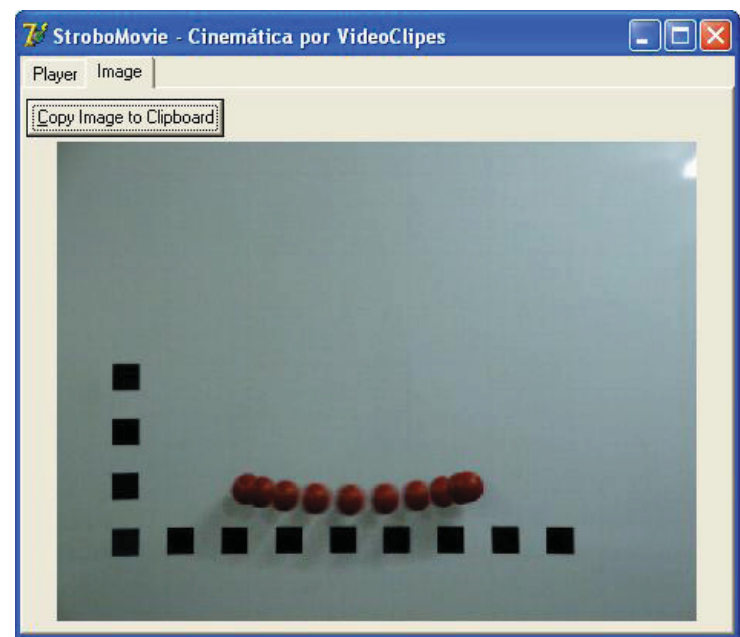

Fig. 9 - Superposição de 10 frames do movimento de um Pêndulo Simples, com duração de um segundo.

O software apresenta, ainda, a opção "Copy Image to Clipboard", que permite copiar a imagem gerada pela superposição dos frames para a área de transferência (Clipboard), e postá-la em outros softwares como, por exemplo, o Paint, o PhotoShop ou o Word. As escalas nas Fig. 7, 8 e 9 são quadrados de 5,0 cm de lados. Com essa escala, é possível medir espacialmente a posição do pêndulo e calcular a função horária do movimento.

Outro exemplo de movimento que pode ser estudado com o StroboMovie é o da queda livre, mostrado na Fig. 10. Nesse caso, um objeto foi solto, em queda livre, da janela de um edifício com mais de quatro metros de parede. Marcações foram feitas na parede a cada meio metro, com fita isolante preta. Observa-se, nesta figura, duas imagens estroboscópicas, a da esquerda, gerada com todos os quadros (Step: 1), e a da direita, usando um a cada dois quadros (Step: 2). Esse recurso possibilita observar com detalhes o movimento de queda livre. Pode-se, por exemplo, construir uma tabela para registro das distâncias percorridas (em intervalos de tempo iguais) e, a partir da equação $\Delta \mathrm{d}=(1 / 2) \mathrm{g}(\Delta \mathrm{t})^{2}$ em que $\Delta \mathrm{d}$ é a distância percorrida, g é a aceleração devido à gravidade e $\Delta$ t é o intervalo de tempo, fazer uma estimativa de g. 


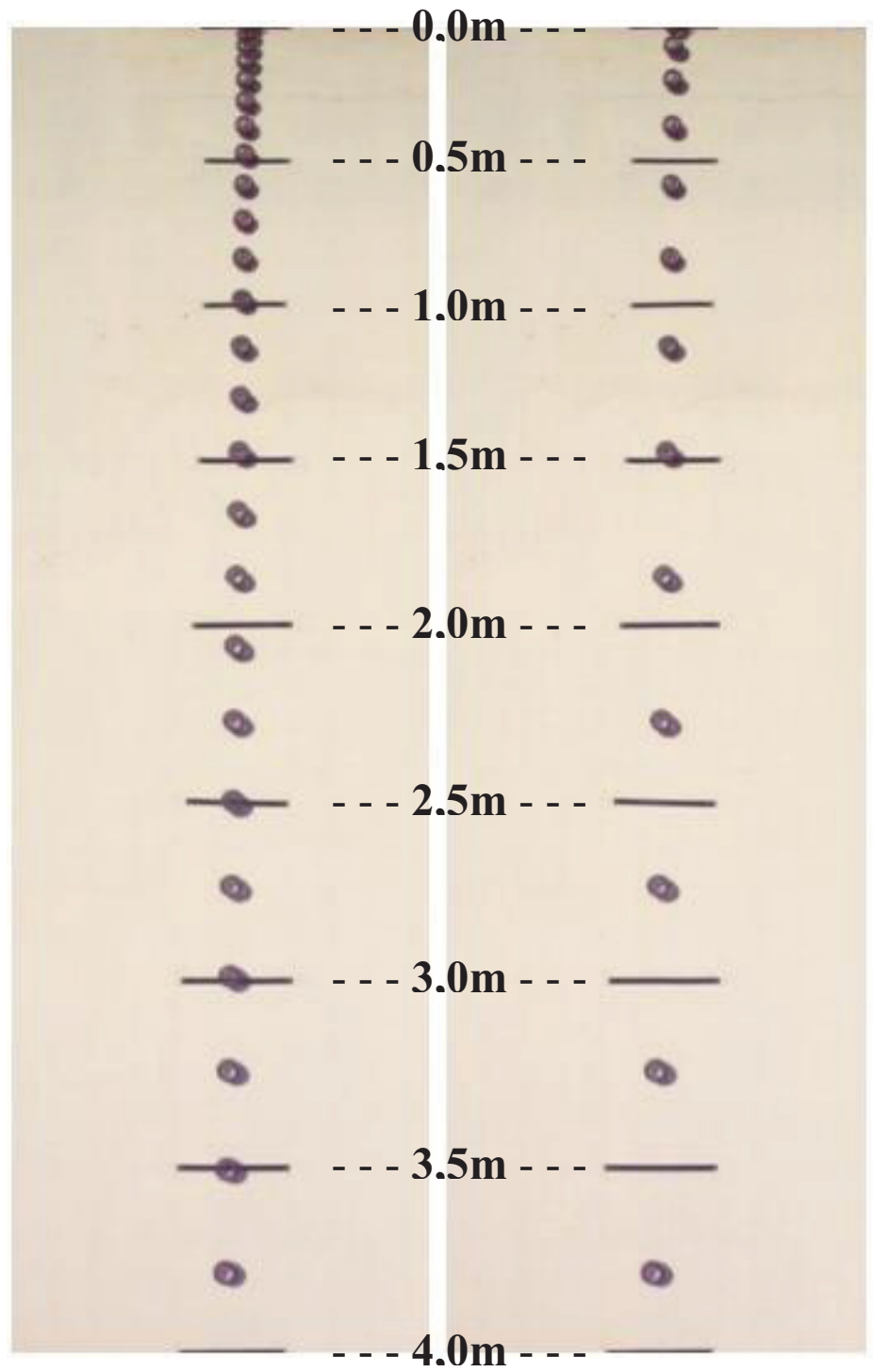

Fig. 10 - Imagem estroboscópica do movimento de queda livre. A imagem à esquerda foi gerada usando todos os quadros (Step: 1); e a da direita usando um a cada dois quadros (Step: 2). 
Um exemplo lúdico de movimento é a tentativa de pessoas em moveremse com velocidade constante (MRU). Na Fig. 11, observa-se a imagem estroboscópica de uma pessoa caminhando concentradamente para manter sua velocidade constante.

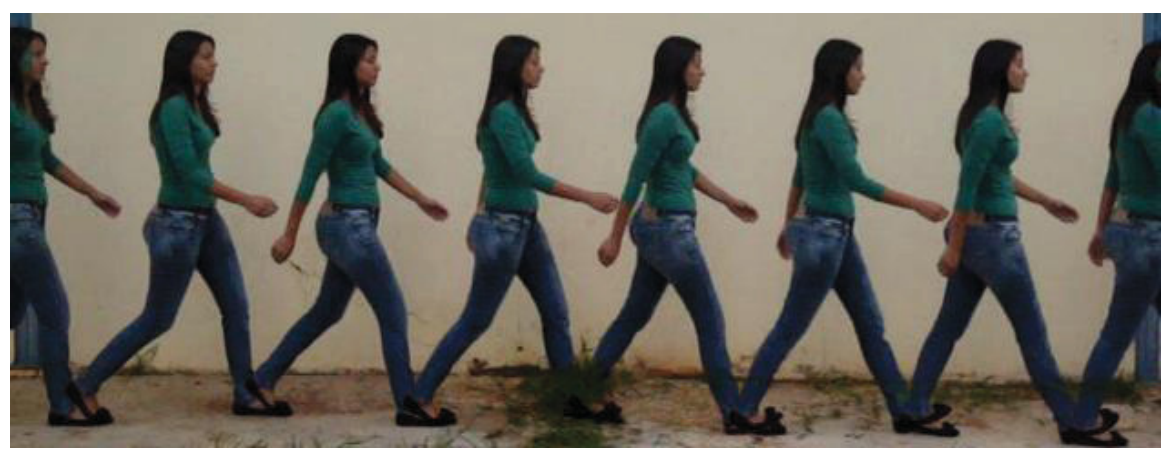

Fig. 11 - Imagem estroboscópica produzida pelo software StroboMovie, com Step: 10, de uma pessoa tentando caminhar com velocidade constante (MRU).

Esse software tem sido empregado com grande sucesso nas aulas de Física Geral I dos cursos de Licenciatura em Física e Licenciatura em Ciências, e também nas aulas de Engenharia Têxtil e Engenharia de Produção, do Campus Regional de Goioerê, da Universidade Estadual de Maringá. Ele também foi utilizado pelos acadêmicos das Licenciaturas nas escolas da rede pública da região durante seus estágios supervisionados, local onde não há tradição de se realizar atividades práticas.

\section{Conclusões}

Com apenas uma câmera digital postada em um tripé, boa iluminação e um computador, é possível, por meio de uma montagem simples, rápida e de baixo custo, estudar os fenômenos básicos do movimento. O software desenvolvido e apresentado neste trabalho permite uma análise pormenorizada dos movimentos. Com ele, os alunos puderam visualizar o movimento por meio dos quadros sobrepostos. Durante o estudo, os alunos acompanharam ativamente todo o processo, desde a captura dos videoclipes às análises qualitativas e quantitativas, colocandoos frente a situações concretas que os fizeram entender a construção do conhecimento científico. Dessa forma, percebemos que essa nova ferramenta didática 
despertou muito a atenção dos alunos, facilitando a compreensão do movimento e, consequentemente, a apropriação do conhecimento.

\section{Referências}

AGUIAR, C. E. Computadores no Ensino de Física. Material didático impresso da disciplina de Informática para o Ensino de Física. CEDERJ: 2006. Disponível em:

$<$ http://omnis.if.ufrj.br/ carlos/infoenci/notasdeaula/roteiros/aula01.pdf $>$. Acesso em: 26 abr. 2012.

AYRES, J. "Delphi Graphics and Game Programming Exposed". Wordware Publishing. 2000 .

BROWN D. Tracker - Video Analysis and Modeling Tool (2012). Disponível em: <http://www.cabrillo.edu/ dbrown/tracker/>. Acesso em: 26 abr. 2012.

BURNS P. T. The history of the discovery of cinematography (2010). Disponível em: <http://www.precinemahistory.net/1870.htm>. Acesso em: 26 abr. 2012.

CORVELONI, E. P. M.; GOMES, E. S.; SAMPAIO, A. R.; MENDES, A. F.; COSTA, V. L. L.; VISCOVINI, R. C. Utilização de máquina fotográfica digital (multi-burst) para aulas experimentais de cinemática - queda livre. Revista Brasileira de Ensino de Física, v. 31, n. 3, p. 3504, 2009.

DIAS, M. A.; AMORIM, H. S.; BARROS, S. S. Produção de fotografias estroboscópicas sem lâmpada estroboscópica. Caderno Brasileiro de Ensino de Física, v. 26, n. 3, p. 492-513, 2009.

GOURVEST, H. DSPack - Components and Class to Multimedia Applications (2010). Disponível em: <http://www.progdigy.com>. Acesso em: 26 abr. 2012.

GUYTON, A. C.; HALL, J. E. Tratado de Fisiologia Médica. 11. ed. Rio de Janeiro: Elsevier, 2006.

MAGALHÃES, M. G. M.; SCHIEL, D.; GUERRINI, I. M.; MAREGA Jr., E. Utilizando tecnologia computacional na análise quantitativa de movimentos: uma atividade para alunos do Ensino Médio. Revista Brasileira de Ensino de Física, v. 24 , n. 2,2002 . 
MINATEL E. SAM - Sistema digital para análise de movimentos do Centro de Divulgação Científico e Cultural (CDCC) (2005). Disponível em: $<$ http://educar.sc.usp.br/sam>. Acesso em: 26 abr. 2012.

PEDUZZI, L. O. Q. Descrição geral de material instrucional utilizado na disciplina Física Geral I do Departamento de Física da Universidade Federal de Santa Catarina (UFSC) (1998). Disponível em: <http://www.fsc.ufsc.br/ pesqpeduzzi/imagens-new4.htm>. Acesso em: 26 abr. 2012.

ROSA, R. A. S.; RAPOZO, R. R.; CARVALHO, T. M.; SABA, M. M. F. Fotografias Estroboscópicas. Física na Escola, v. 5, n. 1, 2004.

SiSMANOGLU, B. N.; GERMANO, J. S. E.; AMORIM, J.; CAETANO, R. A utilização da filmadora digital para o estudo do movimento dos corpos. Revista Brasileira de Ensino de Física, v. 31, n. 1, 2009.

TEIXEIRA, S.; PACHECO, X. Guia do Desenvolvedor Delphi 5. Rio de Janeiro: Campus, 2000. 